\title{
PROPOSTA DE PLANO DE GESTÃO/AÇÃO DE CANDIDATOS À DIREÇÃO NAS ESCOLAS PÚBLICAS: UM PLANO DE METAS
}

\section{PROPOSED MANAGEMENT PLAN/ACTION FOR CANDIDATES TO DIRECTORS IN PUBLIC SCHOOLS: A PLAN OF GOALS}

\author{
Marineia da Rocha ${ }^{1}$
}

Submetido em: 07/06/2021

e26398

Aprovado em: 29/06/2021

\section{RESUMO}

As instituições de ensino necessitam do plano de gestão escolar para que suas ações sejam administradas da forma mais adequada possível. Assim, alcança os objetivos desejados. O objetivo geral do estudo é determinar o sistema de avaliação e reelaboração do plano de gestão escolar no Colégio Estadual Ivanete Martins de Souza, em Piraquara/Paraná, no ano de 2021. A metodologia do estudo é do tipo descritiva, com enfoque qualitativo, um estudo de caso. Alguns teóricos que basearam o estudo foram: Bordignon (1993); Cury (2005); Luckesi(2006); Maia (2010); e Sampieri (2010). O processo de eleição é uma oportunidade para que possamos discutir que escola queremos e qual o perfil do gestor que irá estar à frente da sua administração. Para garantir a sua eficiência, é preciso considerar aspectos diversos que fazem toda a diferença na conquista de um desempenho adequado durante $o$ ano letivo.

PALAVRAS-CHAVE: Mandato de diretor escolar. Plano de gestão escolar. Gestão democrática. Capacidade de Gestão. Desafios da educação pública

\begin{abstract}
An educational institution needs the school management plan so that its actions are managed in the most aligned way possible. Thus, it achieves the desired objectives. The general objective is to determine the system of evaluation and re-elaboration of the school management plan at Colegio Estadual Ivanete Martins de Souza in Piraquara / Paraná, in the year 2021. The descriptive methodology with qualitative focus, a case study. Some theorists on which the study was based were: Bordignon (1993); Cury (2005); Dalben (2004); Favero (2009); Freire (1979); Gasparin (2012); luckesi (2006); Maia (2010); and Sampieri (2010). The election process is an opportunity for us to discuss which school we want and the profile of the manager who will be in charge of its administration. To ensure its efficiency, it is necessary to consider several aspects that make all the difference in achieving an adequate performance during the school year.
\end{abstract}

KEYWORDS: Mandate of school principal. School management plan. Democratic management. Management capacity. Public education challenges.

\section{1.-INTRODUÇÃO.}

Próximos ao momento de saber da comunidade sobre a escolha dos próximos diretores, a maioria das escolas da rede pública de educação, solicitam que os candidatos a diretores (as) elaborem e apresentem suas propostas de plano de gestão/ação.

\footnotetext{
1 Especialização em ESPECIALIZACAO EM TUTORIA EM EAD E DOCENCIA DO ENSINO SUPERIOR pela Universidade Candido Mendes, Brasil (2017) Professora QPM do Colégio Estadual Ivanete Martins de Souza, Brasil
} 


\section{RECIMA21 - REVISTA CIENTÍFICA MULTIDISCIPLINAR ISSN 2675-6218}

PROPOSTA DE PLANO DE GESTÃO/AÇ̃̃O DE CANDIDATOS À DIREĈ̃O NAS ESCOLAS PÚBLICAS: UM PLANO DE METAS

Esse processo de eleição é uma oportunidade para que se possa discutir que escola quer e qual o perfil do novo gestor que irá estar à frente da administração escolar. O plano de gestão apresenta, de maneira coerente e objetiva, as propostas para a gestão da escola para o período do mandato. Com a intenção de ser um plano inicial que será adequado pela comunidade escolar através de discussões coletivas em reuniões.

Mesmo que ainda tenham ocorrido avanços recentes nas gestões anteriores, muitos desafios sempre se mostram prementes para a melhoria da qualidade do ensino ofertada à comunidade. Pois, atualmente o mundo vem se transformando em uma velocidade mais acelerada do que o sistema de educação tradicional, bem como, é necessário destacar os desafios na educação diante da pandemia.

Os avanços tecnológicos, diante a comunicação, com o maior acesso às informações, mudou drasticamente o perfil dos novos alunos. No entanto, nota-se que muitos ainda se encontram presos a uma pedagogia antiquada, ou melhor, ultrapassada, com currículos conteudistas, métodos de avaliação muito falhos, que pouco ou mesmo nada contribuem para a formação, onde os alunos não se sentem favorecidos no processo de ensino e aprendizagem; resultando em alta evasão e reprovação. A gestão escolar, por meio da participação da comunidade escolar, possui as condições necessárias para implementar uma profunda reformulação das práticas gerais de ensino adequando-os aos novos tempos.

A problemática do estudo se dá com a realização da gestão democrática no âmbito da administração das escolas públicas de educação básica do Paraná, se inicia através do uso da premissa de eleição de diretores. É fundamental que o tema gestão democrática seja estudado e debatido no âmbito das unidades escolares, de forma a aprimorar sua assimilação e, por conseguinte, efetivar sua implementação.

De modo que apenas através de transformações na proposição de retirar-se da inércia, em relação à estudo e reflexão da comunidade escolar sobre esse assunto, a gestão democrática das escolas públicas de educação básica do Paraná e todas as demandas que dela são provenientes, implicará na correção e mudança no estado de coisas, substituindo a existência somente no papel, tal como acontece atualmente em parte de nossas escolas. Com o propósito de fomentar e contribuir com esse estudo e reflexão, esse artigo é um início de conversa sobre gestão democrática e elaboração do plano gestor da escola no âmbito das escolas públicas de educação básica do Paraná.

Considerando a relevância do tema, indicamos que, para que a Gestão Democrática se efetive, são necessários alguns mecanismos como: Autonomia: ampliação no espaço de decisão; organização e gestão da escola; escolha de diretores; o projeto político pedagógico escolar (PPP) elaborado nos moldes da gestão democrática; análise, modificação e aprovação do plano de gestão da unidade escolar; regimento interno que defina claramente as funções de cada envolvido no processo de ensino e aprendizagem e a estrutura organizacional da escola, 


\section{RECIMA21 - REVISTA CIENTÍFICA MULTIDISCIPLINAR ISSN 2675-6218}

PROPOSTA DE PLANO DE GESTÃO/AÇ̃̃O DE CANDIDATOS À DIRECÃO NAS ESCOLAS PÚBLICAS: UM PLANO DE METAS

Diante do exposto, faz-se necessária a seguinte análise: Qual é o sistema de avaliação e reelaboração do plano de gestão no Colégio Estadual Ivanete Martins de Souza em Piraquara Paraná, no ano de 2021?

O objetivo geral é determinar o sistema de avaliação e reelaboração do plano de gestão escolar no Colégio Estadual Ivanete Martins de Souza em Piraquara/Paraná, no ano de 2021.

Os objetivos específicos são: 1) Analisar o sistema de avaliação do plano de gestão escolar; 2) Avaliar o sistema de reelaboração do plano de gestão escolar; 3) Propor alternativas de solução dos problemas detectados sobre o sistema de avaliação e reelaboração do plano de gestão.

Os principais autores que fundamentaram este estudo foram: Cury (2005) apud Oliveira (2008), e Paro (2005). Para Cury apud Oliveira (2005) "a gestão democrática nos sistemas públicos de ensino e na própria administração dos serviços públicos vem sendo objeto de reflexões e indagações". Segundo Oliveira (2008), "a garantia de um artigo constitucional que estabelece a gestão democrática não é suficiente para a sua efetivação". Para Paro (2005), "[...] a gestão democrática deve implicar necessariamente a participação da comunidade, parece faltar ainda uma maior precisão do conceito de participação.".

Uma educação inovadora deve preparar o estudante para os novos tempos, como algo que abrange não só conhecimentos e habilidades, mas também atitudes e valores.

Compreender que só se efetiva os resultados esperados através de uma gestão participativa, coletiva e democrática e que atenda os princípios da impessoalidade, eficiência, transparência e compromisso social. Para resistir aos dilemas e consumar as ações propostas é necessário que toda a comunidade escolar esteja engajada em torno de um amplo projeto construído coletivamente e liderado por diretores aptos para tal tarefa.

Geralmente o plano de gestão segue o arcabouço da mantenedora, um modelo a ser seguido e podendo apresentar tópicos; tais como: Biografia dos candidatos, formação acadêmica, atuação profissional, princípios da gestão e as propostas de ação (gestão/administração, ensino, pesquisa e inovação tecnológica, extensão, esporte, cultura e lazer, discentes, servidores), entre outros. $O$ Plano de Gestão deve conter as necessidades e especificidades da instituição de ensino na qual os candidatos pretendem atuar como diretores, elaborado de forma compatível com o projeto político pedagógico da instituição de ensino, bem como de acordo com as políticas educacionais do estado/município, bem como, conhecer as legislações que orientam o currículo e as políticas educacionais da rede de ensino.

Como podemos observar, a gestão democrática na educação está prevista na constituição Federal do Brasil de 1988 e na Lei de Diretrizes e Bases da Educação Nacional de 1996, LDBEN 9.394/96, pressupõe que as relações dentro dos espaços educativos devam ser de cooperação, participação de todos os envolvidos na ação educativa.

A seguir temos como os sistemas de ensino definirão as normas de gestão democrática do ensino público na educação básica, de acordo com as suas peculiaridades os seguintes princípios: 


\section{RECIMA21 - REVISTA CIENTÍFICA MULTIDISCIPLINAR ISSN 2675-6218}

PROPOSTA DE PLANO DE GESTÃO/AÇ̃̃O DE CANDIDATOS À DIRECÃO NAS ESCOLAS PÚBLICAS: UM PLANO DE METAS

I. Participação dos profissionais da educação na elaboração do projeto político pedagógico da escola;

II. Participação das comunidades escolar e local em conselhos escolares ou equivalentes. (BRASIL, 1996, p.12).

De acordo Bordignon (1993) a escola precisa ser concebida, não mais como organização burocrática, mas como instância de articulação de projetos pedagógicos partilhados pela direção, professores, alunos e comunidade.

Ainda Bordignon (1993) na escola não há lugar para burocratas, nem súditos. Nela, todos os envolvidos são cidadãos, atores participantes de um processo coletivo de fazer educação. Educação que se constrói a partir de processos, a cidadania e a democracia.

Segundo as citações acima, seguindo essa perspectiva, cada instituição de ensino deve estabelecer seus sistemas de gestão, fazendo uso dos mecanismos de democratização, para garantir a participação de toda a comunidade escolar em suas ações.

Participaram da pesquisa: dois gestores (diretor geral da escola, diretora auxiliar da escola, membros representantes dos segmentos no conselho escolar da escola), três professores, três funcionários, cinco pais de alunos e um aluno. Os participantes tiveram suas identidades preservadas. A coleta de dados foi realizada por meio de observação, de questionário em formulário estruturado, com a utilização de formulário google e análise documental.

O questionário foi feito com o objetivo de coletar dados, informações e significações contidas nas falas dos participantes. Para o plano gestor escolar foram consideradas as seguintes dimensões: Participantes da elaboração, forma de utilização dos dados da avaliação interna e externa (Prova Paraná e IDEB) para elaboração, reformulação e acompanhamento do plano gestor; participação do conselho escolar na avaliação interna e nas análises das avaliações da escola.

A análise dos documentos permitiu a detecção de dados que necessitavam ser explorados complementando ou confirmando informações. Foram analisados: Regimento escolar, planos de gestão escolar (versões anteriores), atas das reuniões do conselho escolar, relatório de autoavaliação diagnóstica da escola resultante das avaliações internas e externas da escola (Prova Paraná e IDEB). Foi elaborado um roteiro de observação para o acompanhamento do ambiente escolar, reuniões do conselho escolar e de outras reuniões. A observação agregou impressões, registros de fenômenos e contato virtual com as pessoas entrevistadas.

\section{2.- APRESENTAÇÃo do PLANO de GEStÃo PARA COMUNIDAdE ESCOLAR E/OU COMISSÕES.}

De acordo com SEED № 4.252 - 10/11/ 2020, artigo 6으, parágrafo 5, inciso $V$, que trata do processo de consulta à comunidade escolar: Cabe à comissão consultiva local - Instituição de ensino: Convocar assembleia geral com a comunidade escolar, para a apresentação virtual, dos 


\section{RECIMA21 - REVISTA CIENTÍFICA MULTIDISCIPLINAR ISSN 2675-6218}

PROPOSTA DE PLANO DE GESTÃO/AÇÃO DE CANDIDATOS À DIREÇÃO NAS ESCOLAS PÚBLICAS: UM PLANO DE METAS

planos de gestão/ação das chapas inscritas. Partindo deste pressuposto, de que há a necessidade de os candidatos discorrerem sobre o seu plano de gestão, entre as análises possíveis que os participes questionam, estão:

$\checkmark$ Quais as principais ações e estratégias que utilizarão no exercício da função de diretores da instituição de ensino, para que ocorra o maior aprendizado possível dos estudantes;

$\checkmark$ As características de liderança que mais se destacam neles e de que forma as utilizarão no relacionamento com os profissionais da escola;

$\checkmark$ Dentre as principais ações da respectiva secretaria de educação; quais consideram mais eficiente e por quê.

Esses questionamentos foram discutidos com a finalidade sustentar uma gestão favorável ao desempenho do ensino-aprendizado dos estudantes nas escolas assistidas pela pesquisa. Consequentemente, incrementar forças a liderança dos gestores e professores em seus trabalhos. Ainda segundo o parágrafo $5^{\circ}$ alínea "a" do art. 8o da resolução SEED o 4.252 - 10/11/2020 - que trata do processo de consulta à comunidade escolar: Cabe à comissão consultiva local - Instituição de ensino: Caso não seja aprovada a proposta do plano de Gestão/Ação, as comissões consultivas local e regional solicitarão sua readequação, de forma fundamentada, sob pena de indeferimento do registro da chapa, garantindo o contraditório e a ampla defesa.

Pode-se afirmar que a participação de todos os professores da instituição contribuem de forma positiva no processo de construção desse material e, para que a produção escrita seja efetivada, na medida em que propiciam o aprofundamento teórico-prático e reflexões inovadoras, bem como, as avaliações dos participantes; consideradas antes tudo como: coerência das ações e estratégias indicadas pelos candidatos; características de liderança; capacidade de argumentação sobre as políticas educacionais da respectiva secretaria de educação; capacidade de se comunicar com clareza e objetividade.

Todos sabem que a escola, como uma instituição social, se encontra em constante processo de transformação, de renovação de valores, de princípios, de conteúdos, perspectivas e paradigmas. Já se conseguiu muitos avanços em educação, na busca da democratização do ensino e da escolarização básica com qualidade, principalmente no que se refere à igualdade de condições de acesso e permanência na escola.

De acordo com Luckesi:

Será democrática a escola que possibilitar, a todos os educandos que nela tiverem acesso, uma apropriação ativa dos conteúdos escolares. Ou seja, se uma criança se matricula na escola, ela tem o objetivo de conseguir aprender conteúdos que desconhece, ela pretende elevar seu patamar de compreensão da realidade. Para tanto, a prática escolar e, consequentemente, a prática docente deverão criar condições necessárias e suficientes para que essa aprendizagem se faça da melhor forma possível. Isso significa que a prática escolar e docente desenvolverá meios efetivos pelos 


\section{RECIMA21 - REVISTA CIENTÍFICA MULTIDISCIPLINAR ISSN 2675-6218}

PROPOSTA DE PLANO DE GESTÃO/AC̄̃̃ DE CANDIDATOS À DIRECÃO NAS ESCOLAS PÚBLICAS: UM PLANO DE METAS Marineia da Rocha

quais os educandos, de fato, aprendam os conteúdos que estão sendo propostos e ensinados (Luckesi, 2006, p. 65).

A escola é intitulada entre os educadores como um espaço para reflexão, de avaliação da prática pedagógica, de questionamentos acerca das condições de trabalho, das funções de cada parte responsável pelo processo, como das concepções de ensino e de avaliação predominantes e do papel representativo da avaliação e dos participantes dentro desse contexto.

Por tanto, para que haja mudança dessa prática que vivemos na escola, faz-se necessária a participação de todos na busca de novas possibilidades de fazer, assim podemos afirmar ainda que: as práticas seculares e rotineiras na escola não se transformam como num passe de mágica. As pesquisas realizadas demostram a necessidade de muitas discussões entre os professores e sua relação com os alunos. É necessário refletir sobre o significado do que se vem fazendo e, a partir de então, para a construção de uma prática que se adapte a cada realidade da comunidade estudantil.

2.1.- De acordo com a secretaria da educação e do esporte do estado do Paraná, a apresentação da proposta de plano de gestão para a escola - para os quatro anos do mandato (2021 - 2024):

Para elaborar o Plano de Gestão, o candidato deverá escolher uma das 3 (três) escolas escolhidas no ato de inscrição, para atuar como diretor, e utilizando os dados desta escola, disponíveis na página da inscrição, elaborar um Plano de gestão que deverá conter o planejamento de ações e estratégias para solucionar possíveis problemas que a escola possa ter nas frentes de atuação:

$\checkmark$ Melhoria da aprendizagem;

$\checkmark$ Redução da reprovação,

$\checkmark$ Redução do abandono;

$\checkmark$ Superação das fragilidades administrativas (gerenciamento financeiro e vida legal da instituição).

O Plano de Gestão deve apresentar os seguintes itens abaixo:

$\checkmark$ Melhoria da aprendizagem;

$\checkmark$ Redução da reprovação;

$\checkmark$ Redução do abandono;

$\checkmark$ Superação das fragilidades administrativas (gerenciamento financeiro e vida legal da instituição).

Todas as ações planejadas precisam ter como objetivo a garantia do acesso, a permanência e o sucesso escolar, ou seja, ações eficazes que assegurem o bom desempenho da escola num todo. Lembramos que o Plano de gestão para a escola deve considerar a realidade escolar, respeitando antes de tudo a legislação vigente, com ênfase na melhoria da gestão pedagógica, deve ter como objetivo a melhoria da aprendizagem dos estudantes, a melhoria das taxas de aprovação e a diminuição das taxas de abandono escolar. 


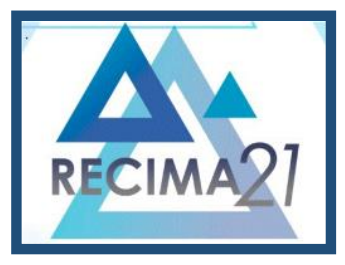

\section{RECIMA21 - REVISTA CIENTÍFICA MULTIDISCIPLINAR ISSN 2675-6218}

PROPOSTA DE PLANO DE GESTÃO/AÇ̃̃O DE CANDIDATOS À DIREĈ̃O NAS ESCOLAS PÚBLICAS: UM PLANO DE METAS

É um instrumento de trabalho dinâmico e flexível, deve ser posteriormente (uma vez selecionado) apresentado e discutido com toda a comunidade escolar e precisa ser construído a partir de algumas premissas, considerando que o diretor é o líder pedagógico que tem como principal função a garantia da aprendizagem dos estudantes.

Conforme a SEED (2020), artigo 68, que trata do processo de consulta à comunidade escolar: A função de diretor ou de diretor auxiliar deverá ser exercida em favor do bom funcionamento administrativo e da função pedagógica, administrativa-financeira e democrática. Parágrafo Único. A gestão democrática deverá garantir um processo político por meio do qual os diferentes atores na escola discutam, deliberem e planejem, solucionem problemas e os encaminhem, acompanhem, controlem e avaliem o conjunto das ações voltadas ao desenvolvimento da instituição de ensino mediante:

I - sustentação do diálogo e da alteridade;

II - participação efetiva de todos os segmentos da Comunidade Escolar;

III - respeito a normas coletivamente construídas para os processos de tomada de decisões;

IV - garantia de amplo acesso às informações aos sujeitos da escola.

Diante dos aspectos apontados anteriormente, o plano de gestão refere-se às ações de competência contextual: as propostas pedagógicas, administrativas e financeiras para execução na escola, considerando as especificidades da comunidade em que a escola está inserida. Todavia, para que haja as mudanças nas práticas vivenciadas na escola, faz-se necessário o envolvimento de todos na busca de uma nova possibilidade de fazer uma melhor gestão.

\section{3.-METODOLOGIA.}

Trata-se de um estudo de caso de uma pesquisa, segundo a abordagem qualitativa, realizado em uma escola estadual de educação básica. Este artigo se refere a um dos aspectos de pesquisa mais ampla concluída recentemente realizada numa escola estadual do estado do Paraná.

Assim sendo, o estudo descritivo procura especificar as propriedades, as características e os perfis importantes de pessoas, grupos, comunidades ou qualquer outro fenômeno que se submeta a análise. Eles medem, avaliam ou coletam dados sobre diversos aspectos, dimensões ou componentes do fenômeno a ser pesquisados (Sampieri, 2010). Segundo (Maia, 2010) o objetivo é descrever especificamente quando e onde as propriedades, características e razões do fenômeno (acima citado) ocorrem.

Numa abordagem qualitativa, utiliza-se como procedimento o estudo de caso de uma escola estadual do estado do Paraná. Para a coleta, foram utilizadas observação, pesquisa documental e um questionário em formulário estruturado, com a utilização do formulário google. Os gráficos podem ser observados nos resultados deste trabalho. Foram sujeitos da pesquisa membros dos segmentos escolares representados no conselho escolar. 


\section{RECIMA21 - REVISTA CIENTÍFICA MULTIDISCIPLINAR ISSN 2675-6218}

PROPOSTA DE PLANO DE GESTÃO/ACÃO DE CANDIDATOS À DIRECÃO NAS ESCOLAS PÚBLICAS: UM PLANO DE METAS

\section{4.-RESULTADOS.}

A revisão de literatura permitiu-nos o embasamento teórico do estudo e, nos forneceu importantes informações acerca do tema em questão, dando-nos a oportunidade de delinear ponderações no que tange à avaliação institucional como instrumento de monitoramento e aprimoramento da gestão da escola pública de educação básica.

Previamente delimitado, o objetivo do presente trabalho foi verificar se os resultados e conclusões da avaliação interna e externa (Prova Paraná e IDEB) da escola têm subsidiado a construção, avaliação, reelaboração do plano de gestão escolar.

Gráfico 01: Ao se candidatar os diretores (diretor e diretor auxiliar) elaboram uma proposta de Plano de Ação referente a sua Gestão?

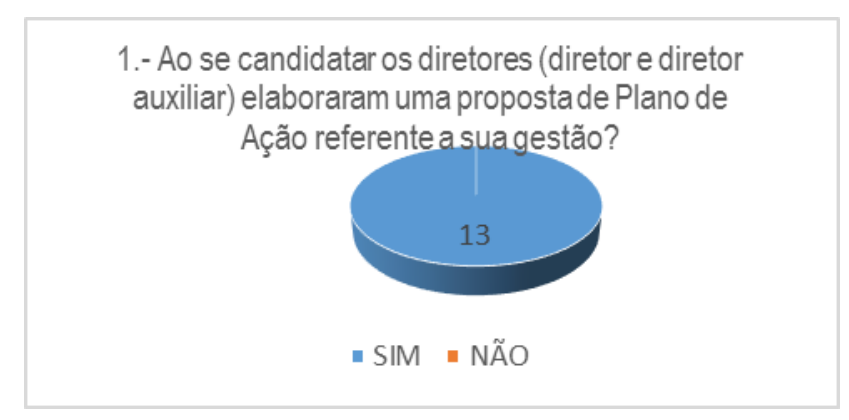

Fonte: Autoria própria (2020-2021).

Analisando o gráfico 01 , podemos comprovar que $100 \%$ dos gestores entrevistados responderam que SIM eles elaboram uma proposta de Plano de Ação referente a sua gestão.

Gráfico 02: Como foi seu envolvimento na construção do Plano de Ação da escola que atua?

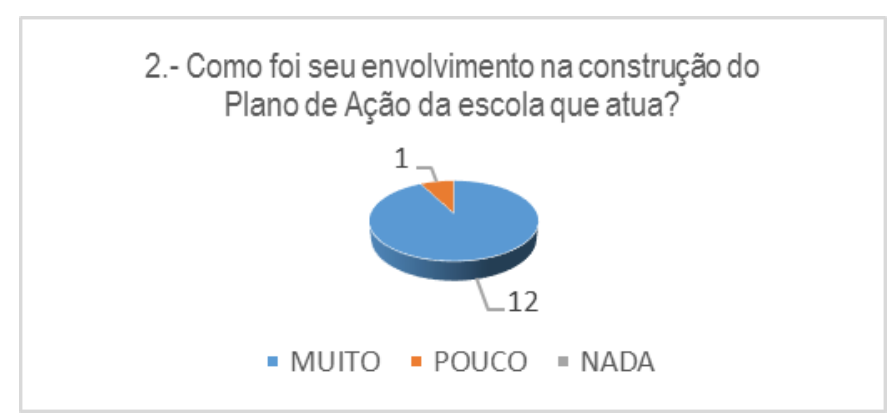

Fonte: Autoria própria (2020-2021).

Analisando o gráfico 02, temos que dos 13 gestores entrevistados, 12 responderam que tiveram MUITO envolvimento na construção do Plano de Ação da escola que atuam e, apenas 1 respondeu que teve pouco envolvimento. 


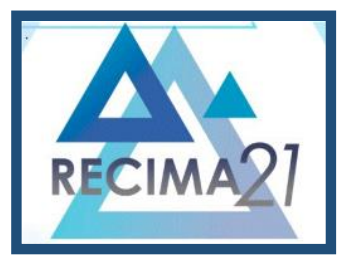

\section{RECIMA21 - REVISTA CIENTÍFICA MULTIDISCIPLINAR ISSN 2675-6218}

PROPOSTA DE PLANO DE GESTÃO/ACÃO DE CANDIDATOS À DIRECÃO NAS ESCOLAS PÚBLICAS: UM PLANO DE METAS

Gráfico 03: Todos os segmentos têm voz e vez na gestão escolar democrática?

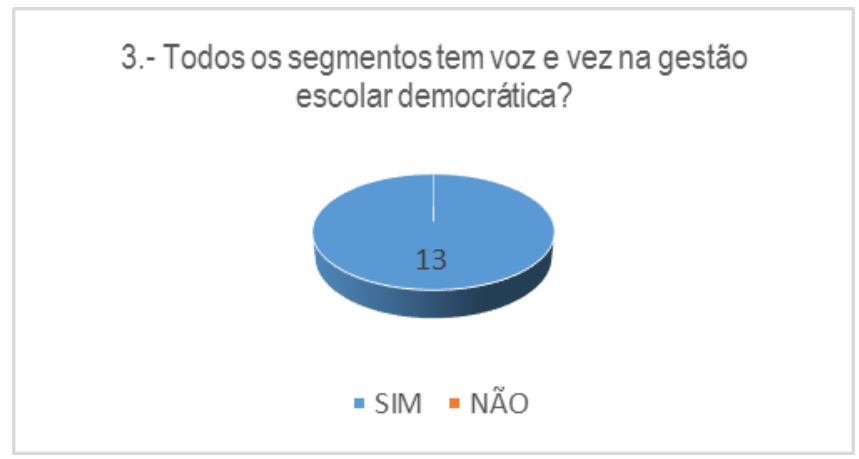

Fonte: Autoria própria (2020-2021).

Analisando o gráfico 3 , temos que os 13 gestores entrevistados responderam que SIM, todos os segmentos têm voz e vez na gestão escolar democrática. Então, como pode-se ver, a democratização na escola acontece de forma favorável ao desenvolvimento da gestão escolar em pauta e ao ensino aprendizado dos alunos, favorecendo a todos envolvidos no processo.

Gráfico 04: Gestores e Equipe pedagógica atuam diretamente com os demais segmentos orientando e decidem ações coletivamente ara melhor qualidade de ensino?

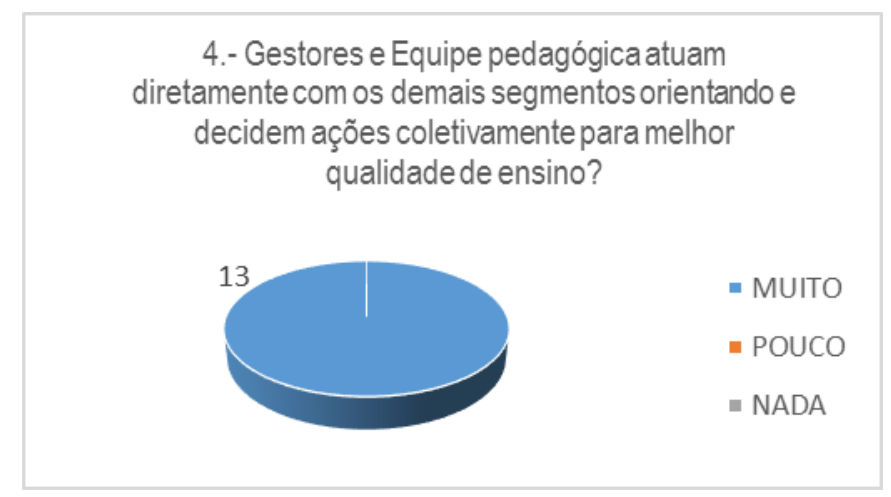

Fonte: Autoria própria (2020-2021)

Analisando o gráfico 4 temos que: os 13 gestores entrevistados responderam que atuam MUITO com os demais segmentos, orientando e decidindo ações coletivamente para melhor qualidade do ensino.

Os resultados da pesquisa indicaram que as avaliações internas e externas (Prova Paraná e IDEB) compõem o plano da gestão escolar institucional, seguidas de análise, interpretação, reflexão e proposta de ação. Verificou-se que é possível suplantar o arcaísmo histórico centralizador na elaboração do plano da gestão escolar, que era demanda da equipe gestora, composta pela equipe diretiva e pela equipe pedagógica. Possibilitando que a comunidade escolar, através da 


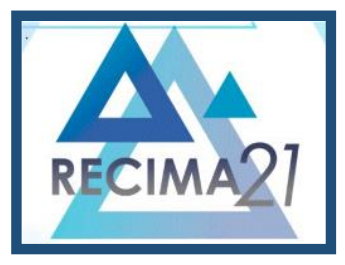

\section{RECIMA21 - REVISTA CIENTÍFICA MULTIDISCIPLINAR ISSN 2675-6218}

representatividade de segmentos no conselho escolar, participe do processo de elaboração, execução, acompanhamento e avaliação.

\section{5.- CONCLUSÃO.}

A dinâmica adotada pelos gestores, isto é, a realização das reuniões de forma virtual, permitiu aos envolvidos: as discussões, interações, trocas de experiências, retomada de conhecimentos e conceitos, relatar angústias e anseios, repensar a prática educacional. Enfim, refletir sobre os temas propostos no plano de gestão.

Apesar de que o tema seja bastante amplo e polêmico, no que se trata à elaboração de um Plano de gestão que deve conter o planejamento de ações e estratégias para solucionar possíveis problemas que a escola possa ter nas frentes de atuação: melhoria da aprendizagem; redução da reprovação, Redução do abandono; e superação das fragilidades administrativas (gerenciamento financeiro e vida legal da instituição).

Se pode presenciar a importância da construção e efetivação do plano de gestão de forma coletiva, com toda a comunidade escolar. Para que mudanças se efetivem na pratica é necessário romper com as práticas tradicionais ou ultrapassadas que impedem o diálogo e a possibilidade de reflexão coletiva (que levam os melhores resultados da ação) e de aprofundamento necessário na busca de soluções. O que se percebe na escola é justamente a ausência desse acordo dialógico, que possibilita o processo de construção e reconstrução do conhecimento.

Como se sabe, o papel da direção na gestão democrática é, principalmente, de propiciar a participação de todos nas decisões, assim tornando-os corresponsáveis pelos resultados. Articular as relações entre todos os segmentos em torno da proposta pedagógica que se quer desenvolver, e primar pela transparência e comunicação nos processos de gestão.

É um rol fundamental, pois pode dificultar ou possibilitar a implantação de procedimentos ou mecanismos de participação. O gestor deve abrir espaços para participação efetiva da comunidade na tomada de decisões, como espaço de discussões das questões e problemas vivenciados pela escola, na construção do projeto político pedagógico (PPP), na participação nas instâncias colegiadas e outras formas de agremiações que representem o interesse da comunidade escolar local.

O presente estudo possibilitou a seguinte conclusão: os fatores que tem colaborado para o compromisso da escola refletir sobre o seu propósito educativo e manifestá-lo, da qual decorre o imperativo da participação da comunidade escolar nos processos de gestão da escola, dos quais o projeto político pedagógico que é um elemento tanto que apresenta o caminho certo a ser seguido, bem como, mostra mecanismos capazes de unir; de ligar uma coisa à outra.

O plano de gestão configura-se para a escola, o documento de maior importância dentro da escola por seu valor legal. A escola se refere a ele como o documento normativo, que para além de um sentido burocrático, ele é o compromisso com a melhoria da qualidade do ensino. 


\section{RECIMA21 - REVISTA CIENTÍFICA MULTIDISCIPLINAR ISSN 2675-6218}

PROPOSTA DE PLANO DE GESTÃO/AÇ̃̃o DE CANDIDATOS À DIRECÃO NAS ESCOLAS PÚBLICAS: UM PLANO DE METAS

Concebe-se, por fim, que a autoavaliação institucional para a gestão escolar é uma ação voltada para resultados, pois ademais ao fato de ser uma ferramenta pedagógica, é um dispositivo político que se eleva acima do restante, pois coaduna com transparência nos resultados que demonstrem a melhoria da qualidade do ensino e dos resultados das atividades educacionais oferecidas à sociedade pela rede pública.

\section{6.- REFERÊNCIAS}

BORDIGNON, G. (1993). Democratização e descentralização da educação: políticas e práticas. Revista Brasileira de Administração Escolar, Brasília, v. 9, 1993.

BRASIL. Lei de Diretrizes e Bases da Educação Nacional (LDB). Lei n. 9.394, de 20 de dezembro de 1996. Brasília: LDB, 1996.

CURY, C. R. J. Gestão Democrática dos sistemas Públicos de Ensino. In.: OLIVEIRA, Maria Auxiliadora Monteiro (Org.). Gestão Educacional: novos olhares, novas abordagens. Petrópolis: Vozes, 2005.

PDN. Instrução 003/2015 - SUED/SEED - estabelece orientações sobre a elaboração do Projeto Político Pedagógico/Regimento Escolar. Londrina: PDN, 2008. Disponível em: http://www.diaadiaeducacao.pr.gov.br/portals/pde/arquivos/1515-6.pdf. Acesso em: 12 dez. 2020.

LUCKESI, C. C. Avaliação da aprendizagem escolar: estudos e proposições. 18. ed. São Paulo: Cortez, 2006.

MAIA, Á. A. Metodologia Científica: pensar, fazer e apresentar cientificamente. Imperatriz, MA: 2010.

OLIVEIRA, F. L. O plano gestor como instrumento na administração escolar. Educação Pública, v. 20, n. 40, out. 2020. Disponível em: https://educacaopublica.cecieri.edu.br/artigos/20/40/o-planogestor-como-instrumento-na-administracao-escolar. Acesso em fev. 2021.

PARO, V. H. Gestão Democrática da Escola Pública. 3. ed. São Paulo: Ática, 2005. 